\title{
METODE BAYES DALAM EVALUASI KINERJA PENYULUH PERTANIAN
}

\author{
Dewi Suranti ${ }^{1}$, Hari Aspriyono ${ }^{2}$ \\ ${ }^{1,2}$ Fakultas Ilmu Komputer, Program Studi Informatika \\ Universitas Dehasen Bengkulu \\ Jl. Meranti Raya No.32 SawahLebar Kota Bengkulu, Bengkulu, KodePos38228 \\ e-mail :dewisuranti@unived.ac.id; hari.aspriyono@unived.ac.id
}

\begin{abstract}
Performance is a very important factor in determining success in assessing work quality. Good performance is the hope of all parties in an institution, including agricultural institutions. The Sukaraja Agricultural Extension Service Technical Unit (UPT BPP) always supports to improve the performance of extension workers in order to improve the quality of extension workers. Evaluation of broadcasting performance is carried out from the beginning of the activities carried out, starting from the preparation, implementation, evaluation and reporting. Evaluation of instructor performance at UPT BPP Sukaraja is carried out every three months and six months. So far, the evaluation is done manually, so it does not need to be done in a timely manner because of constrained inadequate labor. The method used in the evaluation study is the use of agricultural instructors using the Bayes method. The Bayes method is first performed by calculating the value of each criterion, total weighting, probability pecriterian, calculating the total probability, calculating the threshold of each criterion and calculating the threshold value then comparing the total value with the threshold value of each criterion. The results of this method produce a good agriculture instructor ranking ranking, namely with initial Sdnwith a total value of probability 31.38 and those requiring guidance are extension agents with Sjn and Dsm with a total probability of 24.13, and a total probability of 24.
\end{abstract}

Keywords :Bayes, Performance evaluation, Agricultural extensionist

\begin{abstract}
ABSTRAK
Kinerja merupakan faktor yang sangat penting dalam penentu keberhasilan dalam mencetak kualitas kerja. Kinerja yang baik adalah harapan semua pemangku kepentingan pada suatu instansi, termasuk instansi pertanian. Unit Pelaksana Teknis Balai Penyuluhan Pertanian (UPT BPP) Sukaraja selalu berupaya untuk meningkatkan kinerja penyuluh pertanian guna meningkatkan kualitas penyuluh. Evaluasi kinerja seorang penyuluh dapat dilihat dari awal kegiatan yang dilakukan, mulai dari persiapan, pelaksanaan, evaluasi dan pelaporan. Evaluasi kinerja penyuluh di UPT BPP Sukaraja dilaksanakan setiap tiga bulan dan enam bulan sekali. Selama ini, evaluasi dilakukan secara manual, sehingga tidak dilakanakan dengan tepat waktu karena terkendala tenaga kerja yang tidak memadai. Motode yang digunakan dalam kajian evaluasi kinerja penyuluh pertanian ini menggunakan metode Bayes.Metode Bayes dilakukan pertama kali dengan menghitung nilai bobot setiap kriteria, total bobot, probabilitas perkriterian, mengitung total probabilitas, menghitung ambang setiap kriteria dan menghitung nilai ambang keseluruhan kemudian membandingkan nilai
\end{abstract}


total probabilitas dengan nilai ambang setiap kriteria. Hasil metode ini menghasilkan komposisi rangking penyuluh pertanian yang baik, yaitu dengan inisial Sdn dengan nilai total probabilitas 31,38 dan yang membutuhkan pembinaan adalah penyuluh dengan inisial Sjn dan Dsm dengan total probabilitas 24,13, dan total probabilitas 24.

Kata Kunci :Bayes, Evaluasi kinerja, Penyuluh pertanian

\section{Pendahuluan}

Penilaian kinerja yang baik adalah harapan semua pemangku kepentingan pada suatu instansi, termasuk instansi pertanian. Terkait penilaian kinerja seorang penyuluh dapat dilihat dari awal kegiatan yang dilakukan, mulai dari persiapan, pelaksanaan, evaluasi, dan pelaporan. Adapun komponen pendukung lainnya yang menunjang keberhasilan seorang penyuluh terlihat dari aspek penilaian kepemimpinan, komunikasi, serta penguasaan teknis. Aspek penilaian tersebut merupakan rangkaian kerja yang tidak dapat dipisahkan dari program kerja seorang penyuluh didasarkan pada analisis kebutuhan petani yang mencerminkan sasaran keberhasilan yang ingin dicapai [1].

Menurut informasi koordinator penyuluh, Unit Pelaksana Teknis Balai Penyuluhan Pertanian (UPT BPP) Sukaraja Kabupaten Seluma masih tergolong kekurangan tenaga penyuluh pertanian. Data yang diperoleh UPT BPP Sukaraja memiliki 20 orang penyuluh membina 22 desa/kelurahan dengan jumlah 88 kelompok tani binaan. Dijelaskan dalam UU No. 16 Tahun 2006 bahwa, satu tenaga penyuluh hanya dapat membina satu desa. Namun faktanya, masih ditemukan penyuluh pertanian yang mendapat tugas membina lebih dari satu desa. Hal ini menyebabkan belum menunjukan dampak yang signifikan terhadap keberdayaan dan kemandirian petani. Tujuan penelitian ini adalah untuk mengetahui kinerja penyuluh sehingga diharapkan terselenggaranya penyuluhan yang produktif, efektif, efisien, terdesentralisasi, partisipatif, terbuka, berswadaya, bermitra sejajar, kesetaraan gender, serta terwujudnya penyuluh yang berwawasan luas ke depan diwilayah binaan UPT BPP Sukaraja.

Penelitian ini menerapkan pengembangan sistem model Waterfall. Tahapannya dimulai dari pengumpulan data, analisis, hingga implementasi dan pengujian sistem. Decision support akan mempermudah evaluasi kinerja penyuluh di wilayah UPT BPP Sukaraja ini dengan kajian Bayes yaitu, [2] mengatakan metode pengklasifikasian menggunakan metode probabilitas dan statistik yang 
berdasar pada teorema Bayes. Tujuannya adalah tersedianya pengelolahan informasi, sehingga dapat membantu dalam pengambilan keputusan dengan memilih berbagai alternatif terbaik.

Kajian terdahulu yang menjadi patokan dalam melakukan penelitian ini di antaranya adalah: 1) penelitian [3] tentang implementasi metode bayes pada penilaian kinerja dosen dengan kriteria yang digunakan yaitu kriteria kinerja dasar, penyampaian materi, Kesesuaian dan Penguasaan Materi. Namun, hasil perhitungan yang diperoleh belum terlihat jelas kinerja dosen pada tempat penelitian; 2) penelitian [4] yang bertujuan untuk mengatasi permasalahan pegawai bagian kredityang mengalami kesulitan dalam melakukan penentuan kelayakanpemberian kredit. Adanya penelitian ini mempermudah pengambilan keputusan dapat berjalan dengan cepat dan akurat dalam pemberian kredit kepada masyarakat;3) penelitian [5] guna mengkalsifikasi kinerja pemerintah desa dalam mengelola dana desa dengan kriteria yang digunakan 7 kriteria. Melalui menerapkan bayes, kinerja pemerintah desa dapat dievaluasi dengan memberikan pemeringkatan kinerja pemerintah desa yang baik dan buruk dalam pengelolaan dana desa dengan mempertimbangkan kriteria yang lebih detail dan penelitian ini menghasilkan solusi yang dapat digunakan dalam mengontorl kinerja pemerintah desa dalam mengelola dana desa.

Perbedaan penelitian ini dengan adalah menjelaskan secara detail langkahlangkah perhitungan metode Bayes. Dengan mengembang metode Bayes dalam evaluasi penyuluh pertanian di UPT BPP Sukaraja dapat mengetahui bahwa dengan menerapkan metode dalam sistem pendukung keputusan dalam evaluasi dapat menghasilkan evaluasi yang baik.

\section{METODE PENELITIAN}

\section{Metode Bayes}

Kinerja penyuluh dapat dinyatakan baik atau tidak, evaluasi harus dilakukan sesuai dengan kriteria yang telah ditetapkan dalam Permenta, 2013. Nilai harapan merupakan nilai rata-rataa setiap kriteria. Nilai tersebut diperoleh dari bobot setiap kriteria dibagi dengan jumlah bobot keseluruhan. Menurut [4][7] tahapan dalam metode bayes digunakan persamaan berikut :

1. Menghitung Nilai Bobot Setiap Kriteria

$$
\mathrm{B} k=\sum_{i=1}^{n}\left(\sum_{j=1}^{o i} o i\right)
$$

Pada persamaan 11, i adalah pernyataan ke, $\mathbf{n}$ adalah jumlah pernyataan, $\mathbf{j}$ adalah option ke, oi 
adalah jumlah option dari pernyataan $\mathbf{i}$ dan Bk adalah bobot dari setiap kriteria.

2. Menghitung Nilai Bobot Total

$$
\text { Btotal }=\sum_{k=1}^{l} B k(2)
$$

Pada persamaan $12, \mathbf{k}$ adalah kriteria ke, $\mathbf{l}$ adalah jumlah kriteria, Bk adalah bobot setiap kriteria, Btotal adalah total dari bobot. Langkah selanjutnya menghitung probabilitas dari masing-masing kriteria dengan persamaan 3 .

3. Menghitung Nilai Probabilitas

$$
\mathbf{P} \boldsymbol{k}=\frac{\mathrm{B} \boldsymbol{k}}{\mathrm{B} \text { total }}
$$

Pada persamaan 3, B $\boldsymbol{k}$ adalah bobot dari setiap kriteria, Btotal adalah bobot total, $\mathbf{P} \boldsymbol{k}$ adalah probabilitas per kriteria.

Evaluasi penyuluh pertanian dikatakan baik berdasarkan kriteria yang telah ditatapkan jika skor yang dihasilkan $\geq$ nilai ambang dari setiap kriteria (Ak) [4]. Nilai ambang kriteria dinyatakan sebagai ketetapan. Nilai ambang setiap kriteria diperoleh dengan menggunakan persamaan 4.

$$
\mathbf{A} k=\frac{B k}{2} \times \mathbf{P} k
$$

Persamaan 14, Bk adalah bobot setiap kriteria, Pk adalah probabilitas per kriteria. Jika skor evaluasi kinerja penyuluh yang ditetapkan baik dari setiap kriteria adalah Yk, maka parameter skor yang ditetapkan adalah pada persamaan 5 .

$$
\mathbf{B}=\left\{\begin{array}{c}
\mathbf{Y} \boldsymbol{k}>\mathbf{A} \boldsymbol{k}=\mathbf{B} \\
\mathbf{Y} \boldsymbol{k} \leq \mathbf{A} \boldsymbol{k}=\mathbf{T B}
\end{array}\right.
$$

4. Menghitung nilai ambang keseluruhan

$$
\text { Atotal }=\mathbf{A 1}+\mathbf{A} 2+\mathbf{A} 3 \ldots . . \mathbf{A}_{\mathbf{n}}(6)
$$

Perasamaan $16,1,2,3, \ldots$ n adalah indeks dari setiap kriteria.

Apabila $\mathrm{Y}$ adalah total nilai pendataan dari semua criteria maka penilaian kinerja penyuluh dikatakan baik (B) jika nilai didapat > dari nilai ambang total (Atotal), dan dikatakan tidak baik (TB) jika nilai didapat $\leq$ dari nilai ambang total $\left(\mathbf{A}_{\text {total }}\right)$, seperti pada persamaan 7 .

$$
\mathbf{Y}=\left\{\begin{array}{c}
\mathbf{Y}>\text { Atotal }=\mathbf{B} \\
\mathbf{Y} \leq \text { Atotal }=\mathbf{T B}
\end{array}\right.
$$

Berdasarkan hasil evaluasi kinerja penyuluh yang didapat jika penilaian dikatakan baik (B), maka dapat dikelompokkan lagi termasuk dalam criteria sangat baik atau tidak. Kinerja penyuluh dikatakan sangat baik (SB) jika nilai yang diperoleh > dari nilai ambang baik ( $\mathbf{A}_{\text {sangat baik }}$ ) [8], sehingga seperti persamaan 8 dan persamaan 9 .

$$
\begin{aligned}
& \text { SB }= \\
& \left\{\begin{array}{c}
A_{\text {total }}<Y \leq A_{\text {Sangat Baik }}=B \\
Y \geq A_{\text {Sangat Baik }}=S B
\end{array}\right.
\end{aligned}
$$

$$
\begin{aligned}
& \quad\left(\mathbf{A}_{\text {Sangat Baik }}\right)=\left(2 \times \boldsymbol{A}_{\text {total }}\right) \times \\
& \mathbf{3} / \mathbf{4} \quad(9) \\
& \text { Untuk menghitung nilai pendataan dari } \\
& \text { setiap kriteria pada persamaan } 10 .
\end{aligned}
$$

$$
\mathbf{X} k=\mathbf{X}_{\mathbf{1}}+\mathbf{X}_{\mathbf{2}}+\mathbf{X}_{\mathbf{3}} \ldots \mathbf{X}_{\mathbf{n}}(10)
$$

Pada persamaan $9, X_{k}$ adalah skor hasil pendataan setiap criteria, $X_{1}, X_{2}, X_{3}, \ldots X_{n}$ adalah jawaban dari setiap pernyataan masing-masing kriteria. Skor pendataan diperoleh dengan persamaan 11 .

$$
\text { Hasil }=\mathbf{X}_{\mathbf{k}}+\mathbf{P}_{\mathbf{k}}
$$




\section{HASIL DAN PEMBAHASAN}

Kriteria dalam evaluasi kinerja dilakukan dengan cara menentukan beberapa komponen keberhasilan penyuluh pertanian yang ditetapkan oleh Dinas Pertanian. Penerapan metode Bayes dalam evaluasi kinerja menggunakan 16 kriteria yang diajukan dalam pengambilan keputusan sesuai dengan [9], dapat dilihat pada Tabel 1.

Tabel 1.Kriteria Evaluasi Kinerja Penyuluh Pertanian

\begin{tabular}{|c|c|c|}
\hline Kriteria & Kode & Pernyataan \\
\hline $\begin{array}{l}\text { Persiapan } \\
\text { Penyuluh } \\
\text { an }\end{array}$ & $\overline{\mathrm{K}_{1}}$ & $\begin{array}{l}\text { Membuat data potensi } \\
\text { wilayah dan agro } \\
\text { ekosistem }\end{array}$ \\
\hline Pertanian & $\mathrm{K}_{2}$ & $\begin{array}{l}\text { Memberikan } \\
\text { bimbingan penyusunan } \\
\text { Rencana Definitif } \\
\text { Kebutuhan Kelompok }\end{array}$ \\
\hline & $\mathrm{K}_{3}$ & $\begin{array}{l}\text { Menyususnan } \\
\text { programa penyuluh } \\
\text { pertanian }\end{array}$ \\
\hline & $\mathrm{K}_{4}$ & $\begin{array}{l}\text { Membuat rencana kerja } \\
\text { tahunan penyuluh } \\
\text { pertanian }\end{array}$ \\
\hline \multirow{6}{*}{$\begin{array}{l}\text { Pelaksan } \\
\text { aan } \\
\text { Penyuluh } \\
\text { Pertanian }\end{array}$} & $\mathrm{K}_{5}$ & $\begin{array}{l}\text { Melaksanakan } \\
\text { deseminasi/penyebaran } \\
\text { materi penyuluhah }\end{array}$ \\
\hline & $\mathrm{K}_{6}$ & $\begin{array}{l}\text { Melaksanakan } \\
\text { penerapan metode } \\
\text { penyuluhan pertanian } \\
\text { dalam bentuk } \\
\text { kunjungan }\end{array}$ \\
\hline & $\mathrm{K}_{7}$ & $\begin{array}{l}\text { Melaksanakan } \\
\text { penrapan metode } \\
\text { penyuluhahn dalam } \\
\text { bentuk demontrasi }\end{array}$ \\
\hline & $\mathrm{K}_{8}$ & $\begin{array}{l}\text { Melaksanakan } \\
\text { penerapan metode } \\
\text { penyuluhan dalam } \\
\text { bentuk temu-temu }\end{array}$ \\
\hline & $\mathrm{K}_{9}$ & $\begin{array}{l}\text { Melaksanakan } \\
\text { penerapan metode } \\
\text { penyuluhan dalam } \\
\text { bentuk kursus }\end{array}$ \\
\hline & $\mathrm{K}_{10}$ & $\begin{array}{l}\text { Melaksanakan } \\
\text { peningkatan kapasitas } \\
\text { petani terhadap akses }\end{array}$ \\
\hline
\end{tabular}

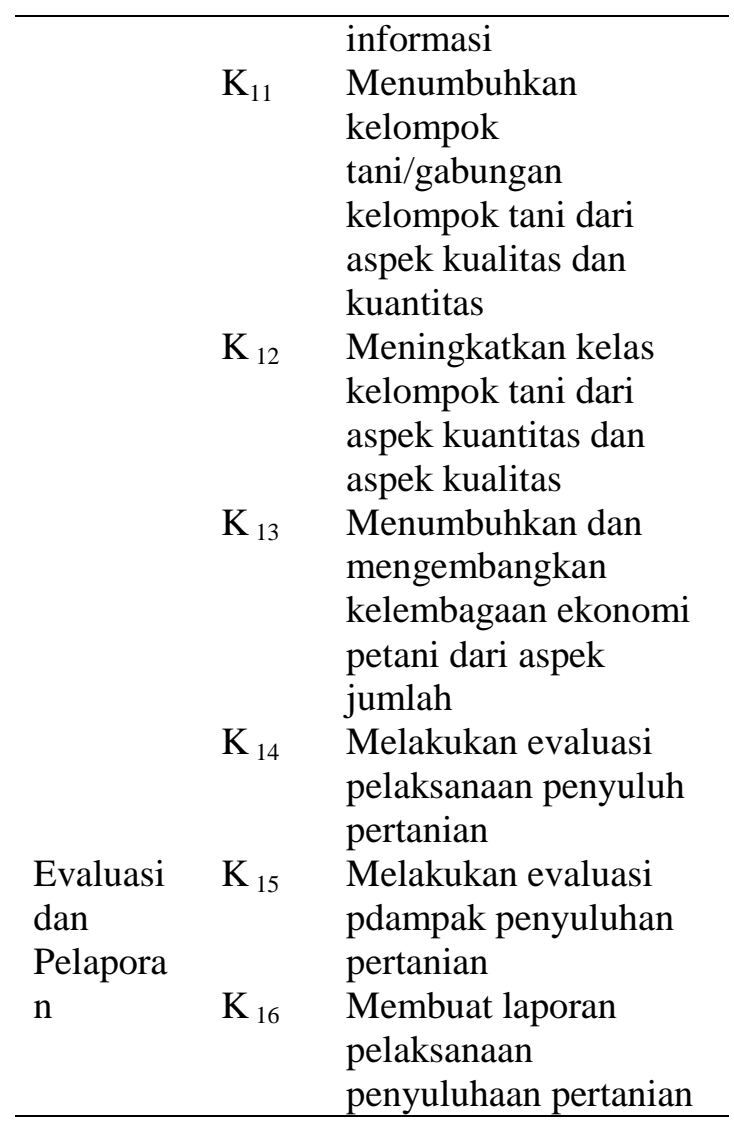

Kriteria yang disajikan pada tabel 1 dapat disajikan tingkat kepentingannya ke dalam kategori bobot yang terlihat pada Tabel 2 .

Tabel 2. Bobot Kriteria

\begin{tabular}{cl}
\hline Bobot & Nilai Bobot \\
\hline 5 & Sangat Baik \\
4 & Baik \\
3 & Cukup \\
2 & Kurang \\
1 & Sangat Kurang \\
\hline
\end{tabular}

Penelitian ini menggunakan 6 penyuluh pertanian sebagai sampel untuk dievaluasi kinerja, dikarena 6 penyuluh ini yang telah menyelesaikan laporan kinerjanya tepat waktu, dapat dilihat pada Tabel 3.

Tabel 3. Data Penyuluh Pertanian Yang Di Evaluasi

\begin{tabular}{cl}
\hline $\begin{array}{c}\text { Inisial } \\
\text { Penyuluh }\end{array}$ & Nama Penyuluh \\
\hline Syh & Syahrial \\
Sjn & Sirajuddin \\
Sdn & Sudirman \\
Es & Eko Susanto \\
\hline
\end{tabular}




\begin{tabular}{cl}
\hline Dsm & Deasy mediana \\
$\mathrm{Akr}$ & Abukery \\
\hline
\end{tabular}

Data evaluasi kinerja penyuluh pertanian berdasarkan instrument evaluasi kinerja penyuluh pertanian UPT BPP Sukaraja berdasarkan instrument yang telah diisi oleh Tim Penilai evaluasi Kinerja di UPT BPP Sukaraja dapat dilihat pada Tabel 4.

Tabel 4. Data Evaluasi Terhadap Penyuluh Pertanian

\begin{tabular}{|c|c|c|c|c|c|c|c|}
\hline \multirow{2}{*}{ Kriteria } & \multirow{2}{*}{ Kode } & \multicolumn{6}{|c|}{ Nilai evaluasi penyuluh } \\
\hline & & Syh & Sjn & Sdm & Es & Dsn & Akr \\
\hline Persiapan & $\mathrm{K}_{1}$ & 5 & 5 & 5 & 3 & 3 & 4 \\
\hline \multirow{3}{*}{$\begin{array}{r}\text { Penyuluhan } \\
\text { Pertanian }\end{array}$} & $\mathrm{K}_{2}$ & 4 & 3 & 5 & 4 & 2 & 3 \\
\hline & $\mathrm{K}_{3}$ & 3 & 3 & 4 & 4 & 4 & 5 \\
\hline & $\mathrm{K}_{4}$ & 4 & 3 & 3 & 4 & 2 & 3 \\
\hline Pelaksanaan & $\mathrm{K}_{5}$ & 2 & 2 & 4 & 3 & 3 & 4 \\
\hline Penyuluh & $\mathrm{K}_{6}$ & 3 & 3 & 3 & 4 & 2 & 5 \\
\hline \multirow[t]{8}{*}{ Pertanian } & $\mathrm{K}_{7}$ & 5 & 5 & 5 & 3 & 5 & 3 \\
\hline & $\mathrm{K}_{8}$ & 5 & 5 & 5 & 5 & 5 & 3 \\
\hline & $\mathrm{K}_{9}$ & 5 & 3 & 5 & 3 & 3 & 5 \\
\hline & $\mathrm{K}_{10}$ & 3 & 3 & 4 & 4 & 4 & 3 \\
\hline & $\mathrm{K}_{11}$ & 4 & 3 & 3 & 4 & 2 & 4 \\
\hline & $\mathrm{K}_{12}$ & 2 & 2 & 4 & 3 & 3 & 5 \\
\hline & $\mathrm{K}_{13}$ & 4 & 3 & 5 & 4 & 2 & 5 \\
\hline & $\mathrm{K}_{14}$ & 3 & 3 & 4 & 4 & 4 & 3 \\
\hline Evaluasi & $\mathrm{K}_{15}$ & 4 & 3 & 3 & 4 & 2 & 4 \\
\hline & \multicolumn{6}{|c|}{ Pelaporan } & 4 \\
\hline Juml & Nilai & 58 & 51 & 66 & 59 & 49 & 63 \\
\hline
\end{tabular}

Proses metode Bayes terdiri dari dua tahap yaitu menentukan nilai ketetapan batas kelayakan dan menilai kinerja penyuluh.

1. Menentukan Nilai Ketetatapan Batas Kelayakan

Untuk mendapatkan nilai dari bobot perkriteria, probabilitas per kriteria, ambang per kriteria maupun ambang Sangat Baik (SB) dilakukan dengan perhitungan sebagai berikut : a. Kriteria Persiapan Penyuluhan Pertanian

$$
\mathrm{B} k 1=5+5+5+5=20
$$

b. Kriteria Pelaksanaan Penyuluh Pertanian

$$
\begin{gathered}
\mathrm{B} k 2=5+5+5+5+5+5 \\
+5+5+5+5=50
\end{gathered}
$$

c. Kriteria Evaluasi dan Pelaporan

$$
\mathrm{B} k 3=5+5=10
$$

b. Menghitung Bobot Total berdasarkan persamaan 2

$$
\text { Btotal }=20+50+10=80
$$

c. MenghitungNilaiProbabilitas per Kriteria, persamaan 3.

a. Kriteria Persiapan Penyuluhan Pertanian

$$
\mathrm{P} k 1=\frac{20}{80}=0,25
$$

b. Kriteria Pelaksanaan Penyuluh Pertanian

$$
\mathrm{P} k 2=\frac{50}{80}=0,625
$$

c. Kriteria Evaluasi dan Pelaporan

$$
\mathrm{P} k 3=\frac{10}{80}=0,125
$$

\section{d. Total Probabiltas}

Ptotal $=0,25+0,625+0,125=1$

e. Mengitung Nilai Ambang per Kriteria, berdasarkan persamaan 4.

a. Kriteria Persiapan Penyuluhan Pertanian

$$
\mathrm{A} k 1=\frac{20}{2} \times 0,25=2,5
$$

b. Kriteria Pelaksanaan Penyuluh Pertanian

$$
\mathrm{A} k 1=\frac{50}{2} \times 0,625=15,625
$$

c. Kriteria Evaluasi dan Pelaporan

$$
\mathrm{A} k 1=\frac{10}{2} \times 0,125=0,625
$$

f. Mengitung Ambang Total sesuai persamaan 6.

$$
\text { Atotal }=2,5+15,625+0,625
$$


g. Ambang Sangat Baik, berdasarkan persamaan 9 .

$$
\begin{aligned}
\text { ASangatBaik } & =(2 \times 18,75) \times \frac{3}{4} \\
& =28,125
\end{aligned}
$$

2. Perhitungan Evaluasi Kinerja Penyuluh

Data penjumlah bobot dari setiap kriteria berdasarkan hasil rekapitulasi penilaian dapat dilihat pada Tabel 5.

Tabel 5. Data Evaluasi Terhadap

\begin{tabular}{|c|c|c|c|c|c|c|}
\hline \multirow{2}{*}{$\begin{array}{l}\text { Kode } \\
\text { Kriteria }\end{array}$} & \multicolumn{6}{|c|}{ Nilai } \\
\hline & Syh & Sjn & $\begin{array}{l}\text { Sd } \\
\text { n }\end{array}$ & Es & Dsm & Akr \\
\hline $\mathrm{K}_{1}$ & 5 & 5 & 5 & 3 & 3 & 4 \\
\hline $\mathrm{K}_{2}$ & 4 & 3 & 5 & 4 & 2 & 3 \\
\hline $\mathrm{K}_{3}$ & 3 & 3 & 4 & 4 & 4 & 5 \\
\hline $\mathrm{K}_{4}$ & 4 & 3 & 3 & 4 & 2 & 3 \\
\hline JumlahBobot & 16 & 14 & 17 & 15 & 11 & 15 \\
\hline $\mathrm{K}_{5}$ & 2 & 2 & 4 & 3 & 3 & 4 \\
\hline $\mathrm{K}_{6}$ & 3 & 3 & 3 & 4 & 2 & 5 \\
\hline $\mathrm{K}_{7}$ & 5 & 5 & 5 & 3 & 5 & 3 \\
\hline $\mathrm{K}_{8}$ & 5 & 5 & 5 & 5 & 5 & 3 \\
\hline $\mathrm{K}_{9}$ & 5 & 3 & 5 & 3 & 3 & 5 \\
\hline $\mathrm{K}_{10}$ & 3 & 3 & 4 & 4 & 4 & 3 \\
\hline $\mathrm{K}_{11}$ & 4 & 3 & 3 & 4 & 2 & 4 \\
\hline $\mathrm{K}_{12}$ & 2 & 2 & 4 & 3 & 3 & 5 \\
\hline $\mathrm{K}_{13}$ & 4 & 3 & 5 & 4 & 2 & 5 \\
\hline $\mathrm{K}_{14}$ & 3 & 3 & 4 & 4 & 4 & 3 \\
\hline JumlahBobot & 36 & 20 & 42 & 37 & 33 & 40 \\
\hline $\mathrm{K}_{15}$ & 4 & 3 & 3 & 4 & 2 & 4 \\
\hline $\mathrm{K}_{16}$ & 2 & 2 & 4 & 3 & 3 & 4 \\
\hline JumlahBobot & 6 & 5 & 7 & 7 & 5 & 8 \\
\hline
\end{tabular}
Penyuluh Pertanian

Nilai setiap kriteria dapat dihitung dengan cara, Hasil jumlah Evaluasi dikali Probabilitas per Kriteria. Adapun Hasil perhitungan sebagai berikut, Hasil keseluruhan dapat dilihat pada Tabel 6 , berdasarkan persamaan 4.

a. Kriteria Persiapan Penyuluhan Pertanian $\mathrm{A} k 1=16 \times 0,25=4$

b. Kriteria Pelaksanaan Penyuluh Pertanian $\mathrm{A} k 2=36 \times 0,625=22,5$

c. Kriteria Evaluasi dan Pelaporan $\mathrm{A} k 3=6 \times 0,125=0,75$

d. Total Probabiltas

$$
\text { Ptotal }=4+22,5+0,75=27,25
$$

Hasil dari setiap perhitungan untuk setiap kriteria untuk setiap penyuluh dapat dilihat pada Tabel 6.Hasil yang diperoleh dengan membandingkan nilai probabilitas total dengan nilai ambang yang diperoleh.

Tabel 6. Data Evaluasi Terhadap Penyuluh Pertanian

\begin{tabular}{lcccccc}
\hline \multirow{2}{*}{ Kriteria } & \multicolumn{6}{c}{ Nilai } \\
\cline { 2 - 7 } & Syh & Sjn & Sdn & Es & $\begin{array}{c}\text { Ds } \\
\text { m }\end{array}$ & Akr \\
\hline Persiapan & 16 & 14 & 17 & 15 & 11 & 15 \\
& $\mathbf{4}$ & $\mathbf{3 , 5}$ & $\mathbf{4 , 2 5}$ & $\mathbf{3 , 7 5}$ & $\mathbf{2 , 7 5}$ & $\mathbf{3 , 7 5}$ \\
Pelaksan & 36 & 20 & 42 & 37 & 33 & 40 \\
aan & $\mathbf{2 2 , 5}$ & $\mathbf{2 0}$ & $\mathbf{2 6 , 2 5}$ & $\mathbf{2 3 , 1}$ & $\mathbf{2 0 , 6}$ & $\mathbf{2 5}$ \\
& & & & $\mathbf{3}$ & $\mathbf{3}$ & \\
Evaluasi & 6 & 5 & 7 & 7 & 5 & 8 \\
& $\mathbf{0 , 7 5}$ & $\mathbf{0 , 6 3}$ & $\mathbf{0 , 8 8}$ & $\mathbf{0 , 8 8}$ & $\mathbf{0 , 6 3}$ & $\mathbf{1}$ \\
Total & 27,2 & 24,13 & 31,38 & 27,7 & 24 & 29,7 \\
Probabilitas & 5 & & & 5 & & 5 \\
$\begin{array}{l}\text { Nilai } \\
\text { Ambang }\end{array}$ & 18,7 & 18,75 & 18,75 & 18,7 & 18,7 & 18,7 \\
Kesimpulan & $\mathbf{4}$ & & & 5 & 5 & 5 \\
Peringkat & & $\mathbf{5}$ & $\mathbf{1}$ & $\mathbf{3}$ & $\mathbf{6}$ & $\mathbf{2}$ \\
\hline
\end{tabular}

Hasil perhitungan Bayes dapat dilihat, bahwa yang memperoleh hasil nilai dengan nilai tertinggi sampai dengan terendah adalah dengan inisial penyuluh sebagai berikut $S d n$, $A k r, E s, S y h$, Sjn dan Dsm. Hasil perhitungan Bayes dapat disimpulkan bahwa Inisial penyuluh $S d n$ merupakan penyuluh pertanian yang memiliki hasil evaluasi kinerja yang sangat Baik. Berdasarkan hasil nilainilai ambangInisial penyuluh $S d n$ mendapatkan peringkat 1 dengan nilai diatas nilai total probabilitas yaitu 31,38, dan Inisial penyuluh Sjn dan $S d m$ merupakan penyuluh pertanian yang membutuhkan rekomendasi pembinaan lebih lanjut oleh koordinator UPT BPP Sukaraja dalam melaksanakan tugas dan tanggungjawabnya sebagai seorang penyuluh. 
Inisial penyuluh tersebut memiliki hasil evaluasi yang Baik yaitu peringkat 5 dengan nilai total probabilitas 24,13 dan 6 dengan nilai total probabilitas 24 .

\section{IV.SIMPULAN}

Hasil dari Bayes dalam mengevaluasi kinerja dapat disimpulkan bahwa menggunakan sampel yang sama dengan metode yang berbeda dari penelitian sebelumnya menghasilkan nilai alternatif yang sama dengan hasil yang baik. Faktor keberhasilan pada penelitian ini adalah jika jumlah nilai keseluruhan kriteria yang diperoleh dari hasil penilaian memiliki jumlah nilai yang tinggi dengan menerapkan metode Bayes dan metode sebelumnya, akan menghasilkan peringkat alternatif yang baik. Dalam penelitian ini, data penyuluh yang dilakukan penilai adalah 6 orang sehingga perhitungan Bayes dilakukan dengan manual. Jika sampel yang dilakukan dalam perhitungan lebih banyak, perhitungan secara manual dinilai tidak efektif. Untuk itu, penelitian harus dilakukan dengan mengembangkan sistem yang lebih akurat. Selanjutnya, penelitian diharapkan dapat dikembangkan dengan metode lain yang ada pada decision support, sehingga dapat dibandingkan dengan hasil penelitian sebelumnya dan dapat dipilih metode yang efektif dalam evaluasi kinerja.

\section{UCAPAN TERIMAKASIH}

Terima kasih atas dukungan Kementerian Riset, Teknologi dan Pendidikan Tinggi Direktorat Jenderal Penguatan dan
Pengembangan Direktorat Penelitian dan PengabdianMasyarakat, Unit Pelaksana Teknik Balai Penyuluh Pertanian Sukaraja dan Masyarakat Universitas Dehasen Bengkulu

\section{DAFTAR PUSTAKA}

[1] Sapar, \& Butami, L. (2017). FaktorFaktor yang Mempengaruhi Kinerja Penyuluh Pertanian dalam Peningkatan Produktivitas Kakao Di Kota Palopo. Jurnal Ekonomi Pembangunan Vol. 03 No. 01 Februari 2017 ISSN 2339-1529, 35-42.

[2] Mustafa, M. S., Ramadhan, M. R., \& Thenata, A. P. (2017). Implementasi Data Mining untuk Evaluasi Kinerja Akademik Mahasiswa Menggunakan Algoritma Naive Bayes Classifier. Citec Journal, Vol. 4, No. 2, Februari 2017 April 2017 ISSN: 2460-4259 , 151-162.

[3] Ari Jayanti, N. K. (2013). Implementasi Metode Bayes Pada Penilaian Kinerja Dosen. Eksplora Informatika Vol. 2, No. 2, Maret 2013 , 101-108.

[4] Astiti, N. M. (2107). Sistem Pendukung Keputusan Pemberian Kredit Pada Lembaga Perkreditan desa Pejeng dengan Menggunakan Metode Bayes. Konferensi Nasional Sistem \& Informatika (pp. 730-736). Bali: STMIK STIKOM.

[5] Fitria -, M. F. (2018). Teknologi Informasi E-Complaint pada Perguruan Tinggi. jurnal Informatika Darmajaya, 116-123. 
.[6] Suranti, D., \& Ikhsan, M. (2017). Performance Appraisal of Seluma Districts Agricultural Extensionist with Fuzzy Simple Additive Weighting Method. Scientific Journal of Informatics Vol. 4, No. 2, November 2017, 169-178.

[7] Herman, M. (2014, 7 13). A MultiCriteria Decision Making Approach to Problem Solving. Brussel, Belgia.

[8] Gunawan, \& Astuti, S. (2013). Sistem Pendukung Keputusan pemilihan gadget Android menggunakan metode Promethee. Techno.Com, 12 (2), 104116.

[9] Pertanian, K. (2013, September 24). Peraturan Menteri Pertanian Nomor 91/Permentan/OT.140/9/2013 tentang Pedoman Evaluasi Kinerja Penyuluh Pertanian. Jakarta, DKI Jakarta, Indonesia. Retrieved from http://perundangan.pertanian.go.id/admin /file/Permentan\%20912013\%20Evaluasi\%20Kinerja\%20Penyu luh\%20Pertanian.pdf

[10] Fitria, Y. A. (2019). Visualization of Data on Earthquake Prone Areasfrom the Analysis of Earthquake Data Vibrations. Test Engineering \& Management, 53015308.

[11] Muliadi, Syarif, S., \& Salim, A. (2019). Penerapan Algoritma Naive Bayes pada Penilaian Kinerja Pemerintah Desa dalam Pengelolaan
Dana Desa. Jurnal Riset Informatika Vol. 1, No. 2 Maret 2019, 71-80. 